\section{A FORTRAN IV program for analyzing higher-order subjective organization units in free recall learning*}

\author{
JAMES W. PELLEGRINO \\ University of Colorado, Boulder, Colorado 80302
}

This paper presents a program for the analysis of subjective organization in free recall and the instructions for the organization of data to use this program. The program is capable of handling lists of up to 40 items, as well as 20 trials of data. In addition, the program provides several types of data tables for unit sizes from 2 to 10 items in length and for three types of sequential ordering criteria.
The following is a description and listing of a FORTRAN IV program to compute subjective organization units according to the techniques described by Pellegrino (1971). The program is applicable to any standard multitrial free recall experiment in which the $E$ wishes to determine the amount of subjective organization that a $S$ has demonstrated. In typical multitrial free recall, a $\mathbf{S}$ is alternately presented a list of items followed by a test trial list members in any sequence desired, with this study-test alternation continuing over several trials in which the same items always constitute the list. Subjective organization refers to the degree to which a $S$ consistently clusters or groups together sets of items from the list over the several test trials required. The measurement of subjective organization is based upon successive pairs of such recall trials (e.g., 1-2, 2-3, 3-4, etc.). Thus, for $t$ trials in a free recall task there are $t-1$ possible trial values that can be obtained. Unlike previous subjective organization programs or techniques, this program [following the procedures described by Pellegrino (1971) for Data Case 1] will examine successive trial pairs for subjective organization units from Size 2 to Size 10 under three increasingly more varied sequential criteria for counting a reproduction of a particular unit.

\section{INDIVIDUAL $S$ DATA CARDS}

The data for each $S$ are punched in representing performance (recall position) on a different list item across all trials, as in the example in Table 1.' The value 00 refers to nonrecall of an item on a particular

*This paper is a publication of the Institute for the Study of Intellectual Behavior, University of Colorado. Research related to the development of this program was conducted under U.S. Public Health Service Fellowship MS8031-0151 to the author from the National Institute of Mental Health. in which he is free to reproduce the the form of a matrix, with each card
Source Deck

This part of the deck consists of the executable FORTRAN statements as provided in the accompanying listing.

\section{General Parameter Card}

This is the only general parameter card for the entire program and contains two values, NS and MS. NS (Cols. 1-3) refers to the number of Ss that are to be processed and MS (Cols. $4-5$ ) is the size of the list. The value of MS must be the same for all Ss to be processed at that time. In the above example, if there were nine Ss and only seven items in the list, this card would be:

trial. The data are stored in matrix $\operatorname{MM}(40,20)$, which is capable of handling 40 -item lists and 20 trials. If either of these values needs to be increased then the DIMENSION and FORMAT statements can be adjusted.

\section{DECK CONSTRUCTION}

The general form of the entire program deck is illustrated in Fig. 1.
Cols. 12345

00907

Individual S Cards

Parameter card. This card provides the parameters for the individual $S$ which are NT, NX, and NSS. NT (Cols. 1-2) refers to the number of trials of data for that $\mathrm{S}$ that are to be examined at this time, providing $\mathrm{NT}-1$ trial
Table 1

\begin{tabular}{|c|c|c|c|c|c|c|c|}
\hline \multirow[b]{2}{*}{ Item } & \multicolumn{6}{|c|}{ Trials } & \multirow{2}{*}{$\begin{array}{c}\text { Columns } \\
\mathbf{1 2 3 4 5 6 7 8 9} \ldots \\
\end{array}$} \\
\hline & 1 & 2 & 3 & 4 & 5 & 6 & \\
\hline $\mathbf{A}$ & $\mathbf{0}$ & 1 & $\mathbf{5}$ & 7 & 4 & 1 & 000105070401 \\
\hline B & 1 & 2 & $\mathbf{0}$ & 1 & 2 & 3 & 010200010203 \\
\hline C & $\mathbf{0}$ & 4 & 3 & 3 & 1 & 4 & 000403030104 \\
\hline $\mathbf{D}$ & 3 & 0 & 2 & 4 & $\mathbf{3}$ & 6 & 030002040306 \\
\hline$\overline{\mathbf{E}}$ & $\mathbf{2}$ & 3 & 4 & 2 & 0 & 7 & 020304020007 \\
\hline $\mathbf{F}$ & 4 & 5 & 6 & 6 & 5 & 5 & 040506060505 \\
\hline $\mathbf{G}$ & 5 & 6 & 1 & 5 & 6 & 2 & 050601050602 \\
\hline
\end{tabular}

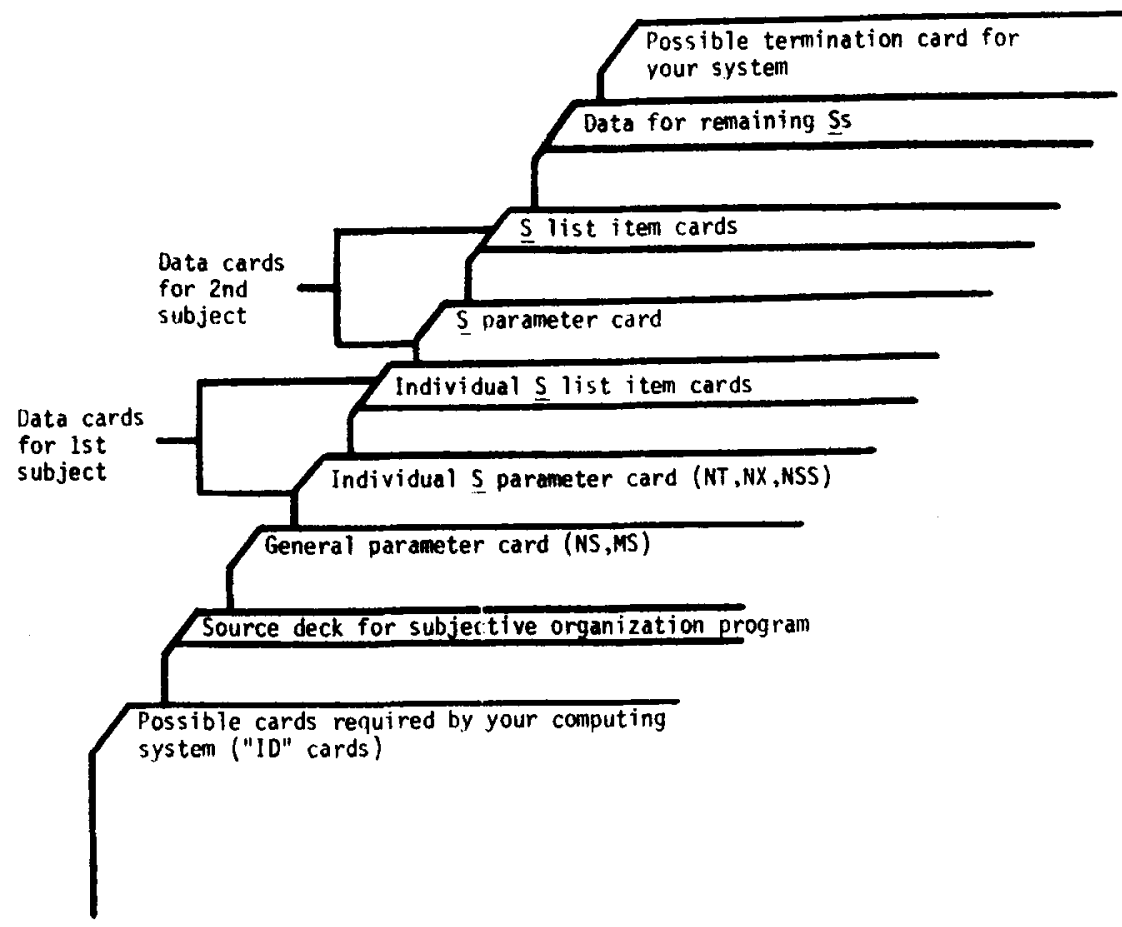

Fig. 1. Arrangement of complete program deck. 
PROGRAM SUBORG (INPUT ,OUTPUT, PUNCH) DIMENSION NN $(40), M M(40,20), J T R(3)$, DIMENSION MAX $(20,9), \operatorname{ITR}(3,20,9)$, READ 1, NS,MS

FORMAT $(13,12) \quad[\times(10), E(3), \operatorname{ARC} 1(3)$ DO $115 \mathrm{~N}=1$,NS $\operatorname{EXP}(3,20,9)$

\section{IBUG $=0$}

READ 2, NT, NX, NSS

2 FORMAT $(2 \mathrm{I} 2, \mathrm{I} 3)$

DO $100 \quad I=1,40$

$N N(I)=0$

DO $100 \mathrm{~J}=1,20$

$100 \operatorname{MM}(I, J)=0$

DO $151 \quad I=1$, MS

3 FORMAT (2012)

151 CONTINUE

DO 99 , ITOT $=1$, NT

DO 99 , ITOT $1=1$, MS

IF (MN(ITOT1, ITOT) .EQ. O) GO TO 99 NN (ITOT $)=N N($ ITOT $)+1$

99 CONTINUE

DO $101 \mathrm{I}=1$,NT

DO $101 \mathrm{~J}=1, \mathrm{NX}$

$\operatorname{MAX}(I, J)=0$

DO $101 \mathrm{~K}=1,3$

$\operatorname{ITR}(K, I, J)=0$

$\operatorname{EXP}(K, I, J)=0$.

$\operatorname{DEV}(K, I, J)=0$.

$101 \operatorname{ARC}(K, I, J)=0$.

NTI $=$ NT -1

DO $114 \quad N=1, N T 1$

DO $113 L=2, N X$

ICTRI $=0$

IF (NN(M) .LT. L) GO TO 114

IF $(N N(M+1)$.LT. L) GO TO 114

DO $102 \quad I=1,3$

$102 \operatorname{JTR}(I)=0$

$I N=N N(M)+1-L$

DO $109 \mathrm{~K}=1$, IN

ICTR2 $=0$

$K K=K$

103 DO $108 \mathrm{~J}=1, \mathrm{MS}$

$\operatorname{IF}(M M(J, M)$.NE. KK) GO TO 108

IF (MM $(J, M+1)$.EQ. O) GO TO 107

I CTR2 = I CTR2+ I

IX $(I$ CTR2 $)=M M(J, M+1)$

IF(ICTR2. NE. L) GO TO 106

ISUMI $=0$

ISUM $=0$

IND $=$ I CTR2 -1

DO $104 \mathrm{NO}=1$, IND

$\mathrm{NP}=\mathrm{NO}+1$

DO $104 \mathrm{NI}=\mathrm{NP}$, ICTR2

NUMI $=I X(N I)-I X(N O)$

NUM2 = I ABS (NUM1)

ISUM $1=$ ISUM $1+$ NUM 1

ISUM2 = I SUM2+NUM2

IF(NUM2 .GE. L) GO TO 109

104 CONTINUE

I $C O N=0$

DO 105 II $=1$, ICTR2

105 I CON $=I$ CON+ (ICTR2-II $) * I I$

$N Y=0$

IF (ICON .EQ. ISUMI) NY=1

IF(NY. EQ. 1) GO TO 666

IF (I CON+ISUMI .EQ. O) NY=2

IF (NY.EQ. 2) GO TO 666

IF (ICON .EQ. ISUM2) NY=3

IF (NY .EQ. 0) GO TO 109

666 DO 667 I $=N Y, 3$

$667 \mathrm{JTR}(\mathrm{I})=\mathrm{JTR}(\mathrm{I})+1$

GO TO 109
$106 K K=K K+1$

GO TO 103

107 ICTRI = ICTR $1+1$

GO TO 109

108 CONTINUE

IBUG $=$ ]

PRINT 9, NSS, M

9 FORMAT $(/, 5 X, 20 \mathrm{HERROR}$ IN SUBJECT N0. , I $4,8 \mathrm{H}$ TRIAL, 14)

109 CONTINUE

IF(IBUG .EQ. 1) GO TO 114

$A=1$.

$B=N N(M)-L+1-I C T R I$

$C=L$

$L I M=L-1$

DO 110 ILL $=1, L I M$

$A B C=L-I L L$

$C=C * A B C$

$D=N N(M+1)-I L L+1$

$A=A * D$

110 CONTINUE

$E(1)=B / A$

$E(2)=E(1) * 2$.

$E(3)=E(1) \star C$

DO $111 \mathrm{I}=1,3$

IF $(B$.EQ. $E(I)) \quad A R C I(I)=0$.

$\operatorname{IF}(B . N E . E(I)) \quad A R C I(I)=(F L O A T(J T R(I))-E(I)) /(B-E(I))$

111 CONTINUE

DO $112 \mathrm{I}=1,3$

$\operatorname{ITR}(I, M, L-1)=J \operatorname{TR}(I)$

$\operatorname{EXP}(I, M, L-1)=E(I)$

$\operatorname{DEV}(I, M, L-1)=F L O A T(J T R(I))-\operatorname{EXP}(I, M, L-1)$

$112 \operatorname{ARC}(1, M, L-1)=\operatorname{ARC} 1$ (I)

$\operatorname{MAX}(M, L-1)=N N(M)-L+1-I C T R 1$

113 CONTINUE

114 CONTINUE

IF (IBUG .EQ. 1) GO TO 115

PRINT 510

510 FORMAT (1H1,52HOBSERVED REPETITIONS FOR ALL THREE ORDERING CRITERIA 1)

PRINT 511

511 FORMAT ( $1 H, 25 X, 6$ HSIZE $2,2 X, 6$ HSIZE $3,2 X, 6$ HSIZE $4,2 X, 6$ HSIZE $5,2 X, 6 \mathrm{HS}$ /IZE $6,2 X, 6$ HSIZE $7,2 X, 6$ HSIZE $8,2 X, 6$ HSIZE $9,2 X, 7 H S I Z E$ 10)

DO $512 \mathrm{~J}=1, \mathrm{NT} 1$

$N I X O N=N X-1$

$\mathrm{JJ}=\mathrm{J}+1$

PRINT 513, (ITR $(1, J, K), K=1, N I X O N)$

513 FORMAT ( $1 H, 10 X, 14$ HUNIDIRECTIONAL, $3 X, 10(12,6 X))$

PRINT $514, J J$, (ITR $(2, J, K), K=1, N I X O N)$

514 FORMAT ( $1 H, 5$ HTRIAL , $1 X, I 2,2 X, 13$ HBIDIRECTIONAL , $4 X, 10(12,6 X))$ PRINT 5I5, (ITR3,J ,K),K=1,NIXON)

515 FORMAT $(1 \mathrm{H}, 10 \mathrm{X}, 9$ HUNORDERED $, 8 \mathrm{X}, 10(12,6 \mathrm{X}))$

512 CONTINUE PRINT 516

516 FORMAT ( $1 H 0,52 H E X P E C T E D$ REPETITIONS FOR ALL THREE ORDERING CRITERIA /)

PRINT 511

DO $517 \mathrm{~J}=1, \mathrm{NT1}$

NIXON=NX-1

PRINT $518,(\operatorname{EXP}(1, \mathrm{~J}, \mathrm{~K}), K=1$, NIXON)

518 FORMAT (IH, 10X,14HUNIDIRECTIONAL, IX,10(F6.3,2X))

$\mathrm{JJ}=\mathrm{J}+1$

PRINT 519, JJ, (EXP $(2, J, K), K=I, N I X O N)$

519 FORMAT( $1 H$, 5HTRIAL, $1 X, I 2,2 X, 13$ HBIDIRECTIONAL , $2 X, 10(F 6.3,2 X)$ )

PRINT $520,(\operatorname{EXP}(3, \mathrm{~J}, K), K=1, N I X O N)$

520 FORMAT(1H , 10X,9HUNORDERED $, 6 \mathrm{X}, 10(\mathrm{~F} 6.3,2 \mathrm{X}))$

517 CONTINUE

PRINT 521

521 FORMAT (1HO, 37HMAXIMUM POSSIBLE OBSERVED REPETITIONS)

PRINT 511

DO $522 \mathrm{~J}=1, \mathrm{NT1}$

NI $X O N=N X-1$

$\mathrm{J}=\mathrm{J}+1$

PRINT 523, JJ, (MAX (J,K), K=1,NIXON) 
523 FORMAT $(1 H, 5$ HTRIAL, $1 X, 12,19 \times, 10(12,6 X))$

522 CONTINUE

PRINT 524

524 FORMAT (1HO,48HDEVIATION SCORES FOR ALL THREE ORDERING CRITERIA)

PRINT 511

DO $525 \mathrm{~J}=1, \mathrm{NT} 1$

NIXON=NX-1

$\mathrm{JJ}=\mathrm{J}+1$

PRINT 518, (DEV $(1, J, K), K=1, N I X O N)$

PRINT $519, j J,(D E V(2, J, K), K=1, N I X O N)$

525 PRINT 520, (DEV $(3, \mathrm{~J}, \mathrm{~K}), \mathrm{K}=1$, NIXON)

PRINT 526

526 FORMAT(1HO,42HARC SCORES FOR ALL THREE ORDERING CRITERIA)

PRINT 511

DO $527 \mathrm{~J}=1$, NTI

NIXON=NX-1

$\mathrm{JJ}=\mathrm{J}+1$

PRINT 518, (ARC $(1, J, K), K=1, N I X O N)$

PRINT 519, JJ, $(\operatorname{ARC}(2, U, K), K=1, N I X O N)$

527 PRINT 520, $(\operatorname{ARC}(3, J, K), K=1, N I X O N)$

PRINT 528, NSS

528 FDRMAT (1H , 14HEND OF SUBJECT $, 2 X, 13$ )

115 CONTINUE

CALL EXIT

END
If a S's data is in error, the program will print out the trial numbers on which the errors occurred. Each error on a trial means that a number is missing from the recall sequence on that trial, e.g., use of the number 12 twice, with 13 missing. The number of error messages for a particular trial indicates how many such errors have occurred.

The program has an internal protection against the possibility of searching for a unit of size $\mathrm{X}$ when either or both trials in the trial pair under examination have a total item recall of less than $X$.

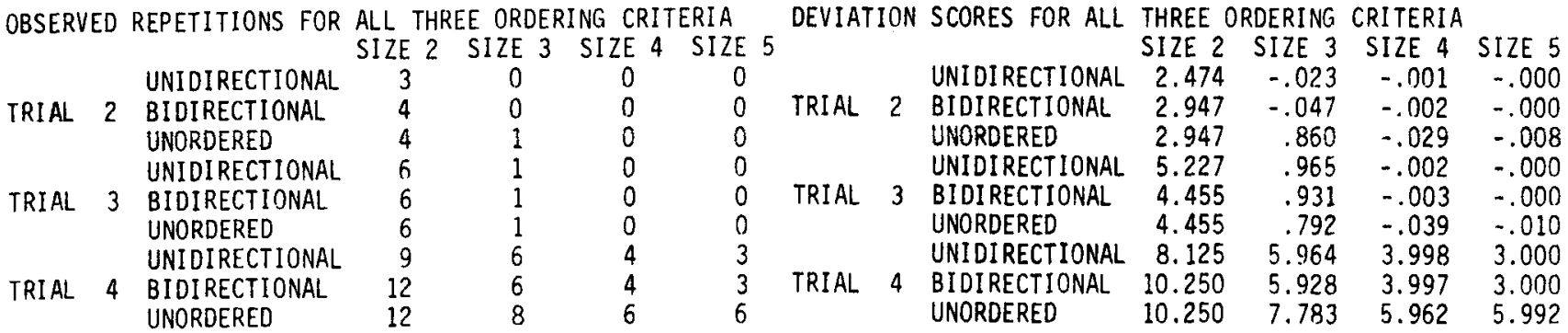

EXPECTED REPETITIONS FOR ALL THFEE ORDERING CRITERIA

\begin{tabular}{|c|c|c|c|c|c|c|}
\hline & & & & & & \\
\hline & & UNIDIRECTIONAL & 26 & .023 & .001 & .000 \\
\hline IIAL & 2 & BIDIRECTIONAL & 1.053 & .047 & $.00 ?$ & .000 \\
\hline & & UNORDERED & 1.053 & .140 & & .008 \\
\hline & & ECTIONAL & .773 & .0 & .00 & .0 \\
\hline IAL & 3 & BIOIRECTIONAL & 1.545 & .069 & .003 & \\
\hline & & & & & & \\
\hline & & RECTIONAL & .8 & .0 & .0 & .0 \\
\hline IAL & 4 & BIDIRECTIONAL & 1. & ? & .0 & \\
\hline & & UNORDERED & 1. & .2. & & \\
\hline & & SIBLE OB & $\begin{array}{l}\text { REI } \\
\text { SIZ }\end{array}$ & $\begin{array}{l}\text { TIONS } \\
\text { SIZF }\end{array}$ & & \\
\hline & 2 & & 10 & 8 & & \\
\hline & 3 & & 18 & 10 & 15 & \\
\hline & 4 & & 21 & 20 & & \\
\hline
\end{tabular}

values. NX (Cols. 3-4) is the size of the largest subjective organization unit that is to be examined, with a maximum of 10 . Thus, the program will compute for unit sizes 2 through NX. NSS (Cols. 5-7) is the S identification number. In the above example, if the maximum size unit to be examined is 5 , then for a hypothetical $S$ number 82 the card would be:

Cols. 1234567 0605082

Individual $S$ data cards. These are the previously described cards which represent the performance on each individual list item across all trials.

The data for each new $S$ immediately follows that of the preceding $\mathbf{S}$. The program processes one $S$ at a time, reading in the MS + 1 data cards for that $S$ and printing out several data tables, as shown in the tables following the program listing. These data include all three ordering criteria, as well as Unit Sizes 2-10. The tables are in the following order: (1) observed number of units, (2) expected values, (3) maximum possible observed units, (4) observed-expected (deviation score), (5) observed-expected/maximum-expected (ARC' ${ }_{\alpha / \mathrm{X}}$ score).
REFERENCES

PELLEGRINO, J. W. A general measure of organization in free recall for variable unit size and internal sequential consistency, Behavior Research Methods \& Instrumentation, 1971, 3, 241-246.

\section{NOTE}

1. The data are punched in this type of matrix to facilitate transfer to several other organizational programs developed by the author. These programs, as well as a deck for the present program, are available upon request (the cost is $\$ 1$ to cover duplication and postage). The additional programs concern input-output organizational analyses, primacy and recency effects, and priority analyses. 